\title{
A Kinetic Study of the Electrochemical Vapor Deposition of Solid Oxide Electrolyte Films on Porous Substrates
}

\author{
Y. S. Lin, L. G. J. de Haart, ${ }^{*}$ K. J. de Vries, and A. J. Burggraaf \\ Laboratory of Inorganic Chemistry, Materials Science and Catalysis, Department of Chemical Technology, University of \\ Twente, 7500 AE Enschede, The Netherlands
}

\section{ABSTRACT}

The electrochemical vapor deposition (EVD) method is a very promising technique for making gas-tight dense solid electrolyte films on porous substrates. In this paper, theoretical and experimental studies on the kinetics of the deposition of dense yttria-stabilized zirconia films on porous ceramic substrates by the EVD method are presented. The more systematic theoretical analysis is based on a model which takes into account pore diffusion, bulk electrochemical transport, and surface charge-transfer reactions in the film growing process. The experimental work is focused on examining the effects of the oxygen partial pressure and substrate pore dimension on the EVD film growth rates. In accordance with the theoretical prediction, the pressure of oxygen source reactant (e.g., water vapor), the partial pressure of oxygen and substrate pore dimension are very important in affecting the rate-limiting step and film growth rate of the EVD process. In the present experimental conditions (e.g., low pressure of oxygen source reactant and small substrate pore-size/thickness ratio), the diffusion of the oxygen source reactant in the substrate pore is found to be the rate-limiting step for the EVD process.

Solid oxide fuel cells (SOFC) are very attractive potential energy conversion systems due to their many advantages over the conventional energy conversion systems. The efficiency of the SOFC, which is theoretically much higher than other fuel combustion-based energy conversion systems, depends on the ionic resistance of the solid oxide electrolyte and electrode materials. It is generally known that reducing the thickness of the solid oxide electrolyte layer can effectively increase the SOFC efficiency (1). Among the several techniques available for making the electrolyte layers, electrochemical vapor deposition has been demonstrated to be a very promising technique for making thin electrolyte layers (films) on porous substrates (2-4), The yttria-stabilized zirconia (YSZ) films of 10-50 $\mu \mathrm{m}$ thick were deposited on porous alumina substrates by the EVD techique (2-6). The integration of a ceramic membrane top layer with a coarse porous substrate makes it possible to deposit much thinner $(<2 \mu \mathrm{m})$ layers. This kind of thin films also has potential applications in membrane separation processes due to their high selectivity in oxygen permeation.

In the EVD process for growing solid oxide electrolyte films, a porous substrate (which serves as an electrode when the SOFC is made) separates a mixture of two metal chlorides and an oxygen source reactant (e.g., a mixture of water and hydrogen, pure water or air). Initially the two reactants interdiffuse in the substrate pore and react to form the corresponding solid oxide product. The solid product under certain conditions $(4,7)$ can be deposited in the substrate pore near the end at the metal chloride delivery side and finally plug the pore part exposed to the metal chloride vapor, After this step no further direct reaction between the two reactants occurs. If the deposited solid oxide is mixed conducting, the metal oxide film may grow on the substrate surface exposed to the metal chloride vapor by the Wagner scaling process (8). In this process, oxygen is reduced at the oxygen/film interface. The oxygen ions transfer in the film and react with the metal chloride at the film/chloride interface to form the solid oxide, which is deposited to keep the EVD film growing.

As such an EVD process is rather difficult to be experimentally monitored, a theoretical study on its film growth kinetics is very important for understanding and controlling the process. In the current literature, very limited data were reported on the film growth kinetics of the EVD process. Carolan and Michaels (6) recently reported a theoretical analysis, with experimental results, on the film growth kinetics in the EVD process. Only the electrochemical transport in the metal oxide film was considered in the analysis. Thus, following almost the identical procedure as employed for deriving thickness-time relations for the Wagner scaling process $(8,9)$, they found that the EVD film

* Electrochemical Society Active Member. growth kinetics can be described by the conventional parabolic law (film thickness is proportional to the squared root of time). This is consistent with some kinetic data of film thickness $v s$, time for growing YSZ film on a porous alumina substrate (6) and tin-doped indium oxide film on a dense YSZ substrate (10).

Some other experimental work on depositing YSZ on porous substrates, however, shows that the deposited film thickness is a linear function of time (2) and the composition of the doped oxide (yttria content) in the film is uniform across the EVD film (11). These results suggest that other mass-transfer step(s) may be the rate-limiting step. In addition, it is found that the experimentally determined film growth rates are much smaller than the predicted ones if electrochemical transport in the electrolyte film is the rate-limiting step, More investigation on the EVD film growth kinetics is therefore needed in order to gain a better insight of the EVD process. In this paper we present a more systematic theoretical analysis on the EVD film growth kinetics, evidenced by new experimental results of growing YSZ films on porous substrates. As suggested by the theoretical analysis, the present experimental study is focused on investigating the film growth kinetics by examining the effects of the oxygen partial pressure and substrate pore dimension on the YSZ film growth rate.

\section{Theoretical}

Model development.-Figure 1 shows a cross-sectional view of the porous substrate separating a mixture of $\mathrm{YCl}_{3}$ and $\mathrm{ZrCl}_{4}$ vapor (in the chloride chamber) and a mixture of water/hydrogen (or air) (in the water chamber). As indicated in Fig. 1, $L$ and $r$ are the thickness and average pore radius of the substrate; $H$ is the thickness of the deposited

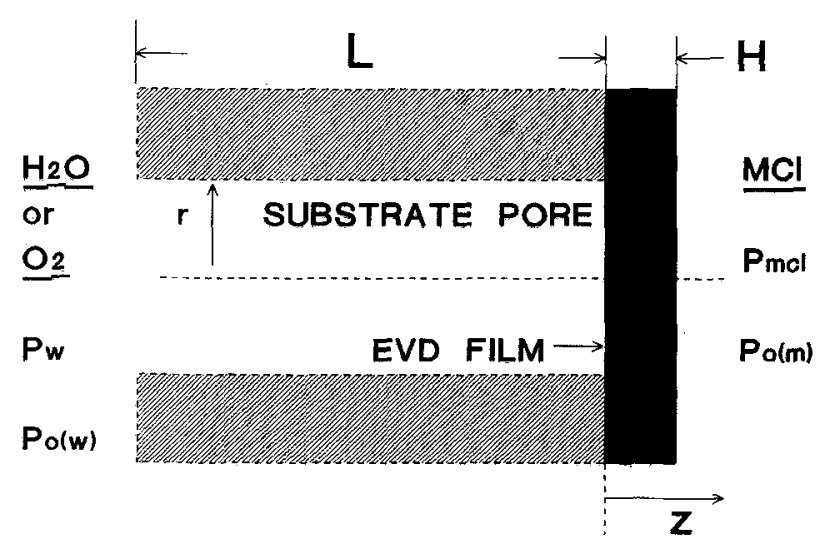

Fig. 1. An idealized cross-sectional view of the EVD process for depositing dense electrolyte film on porous substrate. 
EVD film; $P_{\mathrm{w}}$ and $P_{\mathrm{o}(\mathrm{w})}$ are the partial pressures of water vapor and oxygen in the water chamber; $P_{\mathrm{mcl}}$ and $P_{\mathrm{o}(\mathrm{m})}$ are the total partial pressure of the two chlorides and the partial pressure of oxygen in the chloride chamber.

In the EVD process, water vapor (or oxygen) first diffuses into the substrate pore and, at the water/film interface, is reduced to oxygen ions. The oxygen ions then migrate in the EVD film toward the metal chloride/film interface (electrons move in an opposite direction) and react with metal chloride to form the metal oxide at the film/chloride interface. The growth of the EVD film should be determined by four steps in series: (i) water vapor (or oxygen) diffusion in the substrate pore; (ii) oxygen reduction (charge transfer) reaction at the water/film interface; (iii) bulk electrochemical transport of oxygen ions in the EVD film (counterbalanced by electron/hole migration); and ( $i v)$ charge-transfer (oxidation) reaction for the formation of metal oxide at the film/chloride interface, as shown in Fig. 2. As the fluxes considered in such a film growth process are generally very small, a quasi-steady-state and quasi-thermodynamic equilibrium can be assumed to simplify the modeling.

The water vapor flux rate in the diffusion step in the substrate pore can be described by the following equation for the steady-state diffusion in the axial direction of a cylindrical pore (12)

$$
J_{1(\mathrm{w})}=\left(D_{\mathrm{w}} / L R T\right)\left(P_{\mathrm{w}}-P_{\mathrm{w}(1)}\right)
$$

where $J_{1(w)}$ is the water molar flux, $D_{w}$ is the effective diffusivity of water in the substrate pore, and $P_{w(1)}$ is the water partial pressure at the inner end of substrate pore.

The quasi-equilibrium assumption for the water vapor dissociation reaction gives the relation $P_{w} / P_{w(1)}=\left[P_{o(w)}\right]$ $\left.P_{o(1)}\right]^{1 / 2}$. Thus, the oxygen flux $\left(1 / 2 \mathrm{O}_{2}\right)$ in the substrate pore can be found from Eq. [1] as

$$
J_{1}=\left(D_{\mathrm{w}} P_{\mathrm{w}} / L R T\left[P_{\mathrm{o}(\mathrm{w})}\right]^{1 / 2}\right)\left(\left[P_{\mathrm{o}(\mathrm{w})}\right]^{1 / 2}-\left[P_{\mathrm{o}(1)}\right]^{1 / 2}\right)
$$

where $P_{o(1)}$ is the oxygen partial pressure at the inner end of the substrate pore. If oxygen or air is used as the oxygen source reactant, the flux for $\left(1 / 2 \mathrm{O}_{2}\right)$ should be in the same form as Eq. [1]

$$
J_{1}=\left(2 D_{\mathrm{o}} / L R T\right)\left(P_{\mathrm{o}(w)}-P_{\alpha(1)}\right)
$$

where $D_{0}$ is the effective diffusivity for oxygen $\left(\mathrm{O}_{2}\right)$ in the pore.

At the water/film interface, the oxygen reduction (charge-transfer reaction) rate can be written as (13)

$$
J_{2}=\alpha_{2}\left(\left[P_{\mathrm{o}(1)}\right]^{1 / 2}-\left[P_{\mathrm{o}(2)}\right]^{1 / 2}\right)
$$

where $\alpha_{2}$ is the reduction rate constant and $P_{o(2)}$ is oxygen partial pressure in the EVD film at $Z=0$.
The oxygen anion diffusion and migration in the EVD film from water/film interface to film/chloride interface, balanced by the electron flux transfering in the opposite direction, are similar to the electrochemical transport in the metal oxide scaling process $(8,9)$. For a mixed conducting electrolyte, the following equation can be found for the oxygen anion flux (for $\mathrm{O}^{2-}$ in $\mathrm{mol} / \mathrm{cm}^{2} \cdot \mathrm{s}$ ) at steady state $(6,8,9)$

$$
J_{3}=-\left(t_{i} \sigma_{\mathrm{e}} / 8 \mathbf{F}^{2}\right) \nabla \mu_{o}
$$

where $\nabla \mu_{0}$ is the chemical potential gradient for oxygen in the EVD film; $t_{\mathrm{i}}$ and $\sigma_{\mathrm{e}}$ are the oxygen anion transfer number and electronic conductivity, respectively.

As YSZ is an ionic conducting electrolyte material, $t_{\mathrm{j}} \approx 1$ and the electronic conductivity of YSZ depends on the oxygen partial pressure in the EVD film as $(9,14)$

$$
\sigma_{\mathrm{e}}=\sigma_{n} \mathrm{o}\left[P_{\mathrm{o}}\right]^{-1 / 4}+\sigma_{p}^{\mathrm{o}}\left[P_{o}\right]^{1 / 4}
$$

where $\sigma_{n}{ }^{\circ}$ and $\sigma_{p}{ }^{\circ}$ are the electron and hole conductivities at $1 \mathrm{~atm}$ of oxygen partial pressure. Assuming ideal gas law for oxygen at low pressure, Eq. [5] can be deduced to

$$
J_{3}=-\left(R T \sigma_{\mathrm{e}} / 8 \mathrm{~F}^{2}\right)\left(d\left[\ln P_{\mathrm{o}(\mathrm{film})}\right] / d Z\right)
$$

Substituting Eq. [6] into Eq. [7] and integrating from 0 to $\mathrm{H}$ (with $J_{3}$ constant; quasi-steady-state assumption) yields

$$
\begin{array}{r}
J_{3}=(1 / H)\left(R T / 2 F^{2}\right)\left\{\sigma _ { \mathrm { p } } { } ^ { o } \left(\left[P_{\mathrm{o}(2)}\right]^{1 / 4}-\left[P_{\mathrm{o}(3)}\right]^{1 / 4}+\sigma_{n}{ }^{\mathrm{o}}\left(\left[P_{\mathrm{o}(3)}\right]^{-1 / 4}\right.\right.\right. \\
\left.\left.-\left[P_{\mathrm{o}(2)}\right]^{-1 / 4}\right)\right\}
\end{array}
$$

where $P_{o(3)}$ is the oxygen partial pressure in the EVD film at $Z=H$.

It is also possible to derive the following rate equation for the oxidation reaction (step 4) at the film/chloride interface as

$$
J_{4}=\sigma_{4}\left(P_{o(3)}-P_{o(m)}\right)
$$

where $\alpha_{4}$ is the oxidation rate constant.

The growth rate of the EVD film can be simply found from the mass balance

$$
d H / d t=V_{\mathrm{m}} J / 2
$$

where $J=J_{1}=J_{2}=J_{3}=J_{4}$ and $V_{\mathrm{m}}$ is the average molar volume of YSZ in the EVD film, assumed to be the same as the molar volume of $\mathrm{ZrO}_{2}\left(V_{m}=20.7 \mathrm{ml} / \mathrm{mol}\right)$. This differential equation, with initial condition of $\mathrm{H}=0$ at $t=0$, can be solved together with the oxygen flux Eq. [2] (or [3]), [4], [8], and [9], to give the relation of $H$, as well as $d H / d t, P_{\text {o(1) }}$, $P_{\mathrm{o}(2)}, P_{\mathrm{o}(3)}$ as a function of time. This set of nonlinear algebraic and differential equations were readily solved with a recently proposed numerical method (15).

\section{KINETICS EVD PROCESS}

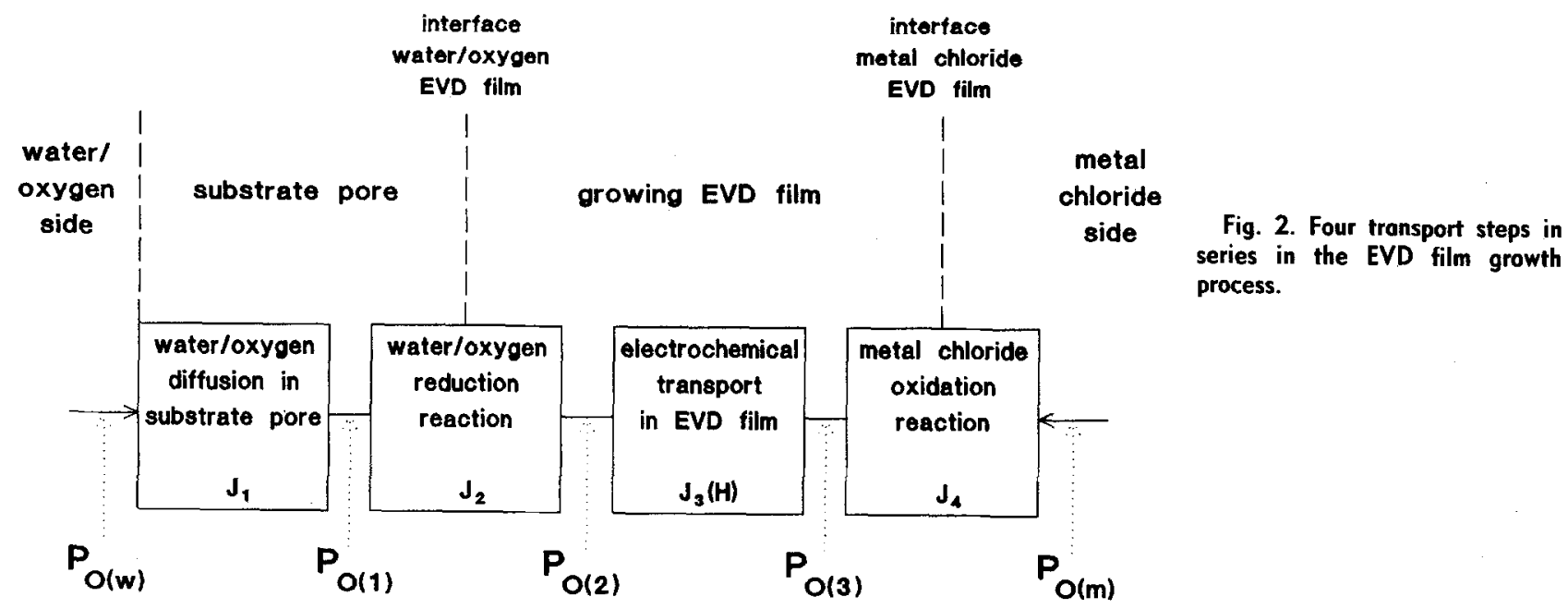


Rate-limiting step.-Observing the above given oxygen flux and film growth equations [Eq. [2], [4], [8], and [9]), it is found that the film growth rate is determined by the substrate pore structure $(r, L)$, the diffusivity of oxygen source reactant in the substrate pore $\left(D_{\mathrm{w}}\right.$ or $\left.D_{\mathrm{o}}\right)$, electrochemical transport properties $\left(\sigma_{\mathrm{p}}{ }^{\circ}\right.$ and $\left.\sigma_{n}{ }^{\circ}\right)$, charge-transfer reaction rate constants $\left(\alpha_{2}\right.$ and $\alpha_{4}$ ), and experimental conditions (controllable parameters $P_{\mathrm{w}}, P_{\mathrm{o}(\mathrm{w})}$, and $T$ ). In principle, all these parameters except $P_{o(m)}$ are known or available from experiments [e.g., oxygen permeation through YSZ pellets (14-17)]. The oxygen partial pressure in the metal chloride vapor, $P_{o(\mathrm{~m})}$, is the value equilibrated with the metal oxides and chlorides in the chloride chamber.

To examine the rate-limiting step in the EVD process, it is suggested that one may calculate the film growth rate for each step assuming it is rate-limiting. With this assumption, the total oxygen partial pressure drop (from $P_{\mathrm{o}(\mathrm{w})}$ to $\left.P_{o(m)}\right)$ is taken to occur across this rate-limiting step. Thus, the following four equations are used for this purpose:

1. The diffusion in the substrate pore (step 1) is rate limiting. For water as the oxygen source reactant

$$
d H / d t=\left(V_{\mathrm{m}} D_{\mathrm{w}} P_{\mathrm{w}} / 2 \operatorname{LRT}\left[P_{\mathrm{o}(\mathrm{w})}\right]^{1 / 2}\right)\left(\left[P_{\mathrm{o}(\mathrm{w})}\right]^{1 / 2}-\left[P_{\mathrm{o}(\mathrm{m})}\right]^{1 / 2}\right)
$$

For $\mathrm{O}_{2}$ or air as oxygen source reactant

$$
d H / d t=\left(V_{\mathrm{m}} D_{\mathrm{o}} / L R T\right)\left(P_{\mathrm{o}(\mathrm{w})}-P_{\mathrm{o}(\mathrm{m})}\right)
$$

2. The oxygen reduction (step 2 ) is rate limiting

$$
d H / d t=\left(V_{\mathrm{m}} \alpha_{2} / 2\right)\left(\left[P_{\mathrm{o}(\mathrm{w})}\right]^{1 / 2}-\left[P_{\mathrm{o}(\mathrm{m})}\right]^{1 / 2}\right)
$$

3. The bulk electrochemical transport in the EVD film (with a thickness of $H=1 \mu \mathrm{m}$ ) (step 3) is rate limiting

$$
d H / d t=K / H(=1 \mu \mathrm{m})
$$

with

$$
\begin{aligned}
K=\left(V_{\mathrm{m}} R T / 4 \mathbf{F}^{2}\right)\left\{\sigma _ { \mathrm { p } } { } ^ { \mathrm { o } } \left(\left[P_{\mathrm{o}(\mathrm{w})}\right]^{1 / 4}-\right.\right. & {\left.\left.\left[P_{\mathrm{o}(\mathrm{m})}\right]^{1 / 4}\right]\right) } \\
& \left.+\sigma_{n}{ }^{\circ}\left(\left[P_{\mathrm{o}(\mathrm{m})}\right]^{-1 / 4}-\left[P_{\mathrm{o}(\mathrm{w})}\right]^{-1 / 4}\right)\right\}
\end{aligned}
$$

4. The oxidation rate of the metal chloride (step 4) is rate limiting

$$
d H / d t=\left(V_{\mathrm{m}} \boldsymbol{\alpha}_{4} / 2\right)\left(P_{\mathrm{o}(\mathrm{w})}-P_{\mathrm{o}(\mathrm{m})}\right)
$$

If the growth rates estimated by these four equations are in the same order of magnitude, there should be no ratelimiting step. If the estimated growth rate for a certain step is much smaller than the others, this step is likely to be the rate-limiting step.

The application of these equations to examine the ratelimiting step of the EVD process will be demonstrated later. In the previous studies, the electrochemical transport in EVD film has been assumed to be the rate-limiting step. In this situation, integration of Eq. [14] gives the following $H(t)$ relation, for the case when $P_{o(w)}$ and $P_{o(m)}$ are very low so that the first term in Eq. [14b] is neglected

$$
H=\left(R T V_{\mathrm{m}} \sigma_{n}{ }^{\circ} / 2 \mathbf{F}^{2}\right)^{1 / 2}\left(\left[P_{\mathrm{o}(\mathrm{m})}\right]^{-1 / 4}-\left[P_{\mathrm{o}(\mathrm{w})}\right]^{-1 / 4}\right)^{1 / 2} V_{t}
$$

which is the same as the model equation developed by Carolan and Michaels [6]. In this situation, $H(t)$ is parabolic. If another step is rate-limiting, a linear $H(t)$ is expected.

The oxygen flux equations also suggest that the oxygen partial pressures, $P_{\mathrm{o}(\mathrm{w})}$ and $P_{\mathrm{o}(\mathrm{m})}$, on both sides of the substrate are very important in determining the rate-limiting step and film growth rate. To show this, the film growth rates at different $P_{o(m)}$ in each step are calculated using Eq. [14], [13], and [11] (or [12]), for the following three cases of different oxygen source reactants (at a total pressure of about $10^{-3}$ atm and a temperature of $1000^{\circ} \mathrm{C}$ ): (i) air,

Table I. Values of the rate parameters at $1000^{\circ} \mathrm{C}$

\begin{tabular}{lcl}
\hline \multicolumn{1}{c}{ Parameter } & Value & \multicolumn{1}{c}{ Remark } \\
\hline$\alpha_{2}\left(\mathrm{~mol}^{\circ} / \mathrm{cm}^{2} \cdot \mathrm{s} \cdot \mathrm{atm}^{1 / 2}\right)$ & $7.5 \times 10^{-11}$ & (from Ref. (13) for CSZ) \\
$\sigma_{\mathrm{p}}\left(\mathrm{ohm}^{-1} \mathrm{~cm}^{-1} \mathrm{~atm}^{-1 / 4}\right)$ & $5.8 \times 10^{-5}$ & (from Ref. (14) for 8 m/o YSZ) \\
$\sigma_{n}\left({ }^{0}\left(\mathrm{ohm}^{-1} \mathrm{~cm}^{-1} \mathrm{~atm}^{1 / 4}\right)\right.$ & $5.7 \times 10^{-9}$ & (from Ref. (14) for 8 m/o YSZ) \\
$D_{\mathrm{w}}\left(\mathrm{cm}^{2} / \mathrm{s}\right)$ & 0.16 & (Knudsen diffusivity for pore \\
$D_{\mathrm{o}}\left(\mathrm{cm}^{2} / \mathrm{s}\right)$ & 0.12 & with $r=0.1 \mu \mathrm{m} ; L=0.2 \mathrm{~cm}$ )
\end{tabular}

$P_{\mathrm{o}(\mathrm{w})}=10^{-3} \mathrm{~atm}$; (ii) pure water vapor, $P_{\mathrm{o}(\mathrm{w})}=10^{-9} \mathrm{~atm}$; (iii) water vapor-hydrogen mixture, $P_{\mathrm{o}(\mathrm{w})}=10^{-15} \mathrm{~atm}$. The simulation results are presented in Fig. 3-5 for the ratelimiting steps of the bulk electrochemical transport, the surface reaction, and the pore diffusion, respectively. The parameter values used for the simulation are obtained from the literature and listed in Table I.

Figure 3 shows the effect of $P_{o(m)}$ at three different $P_{o(w)}$ on the film growth rate for the rate-limiting step of the bulk electrochemical transport. The growth rate increases with decreasing $P_{o(m)}$ in the range of $P_{o(m)}$ being smaller than $P_{o(w)}$. The growth rates become the same for all the three cases of different $P_{\mathrm{o}(\mathrm{w})}$ when $P_{\mathrm{o}(\mathrm{m})}$ is smaller than $10^{-20}$ atm. It is also interesting to note that for a higher $P_{o(w)}$ it is possible to have the growth rate less changed in a larger range of $P_{\mathrm{o}(\mathrm{m})}$. For example, the growth rate decreases from 10 to $1 \mu \mathrm{m} / \mathrm{h}$ with $P_{o(\mathrm{~m})}$ increasing from $10^{-15}$ to $10^{-4}$ atm (11 orders of magnitude) for the case of $P_{o(w)}=10^{-3} \mathrm{~atm}$. However, for the case of $P_{o(w)}=10^{-15}$ atm, the growth rate drops from 10 to $0 \mu \mathrm{m} / \mathrm{h}$ with $P_{\mathrm{o}(\mathrm{m})}$ increasing from $10^{-17}$ to $10^{-15}$ atm ( 2 orders of magnitude). This suggests that a higher oxygen pressure in the water chamber will make it easy to obtain a constant film growth rate, regardless of the possibly large variation of oxygen pressure in the chloride chamber. When oxygen pressure in the chloride chamber is smaller than $10^{-20} \mathrm{~atm}$, varying the oxygen pressure in the water chamber does not change the film growth rate.

The effects of oxygen pressures on the film growth rate for the rate-limiting step of surface reaction or pore diffusion are similar to each other, and also simpler than those for the bulk electrochemical transport as the rate-limiting step, as shown in Fig. 4 and 5. For different $P_{o(w)}$, the film growth rate is in a constant maximum value when $P_{o(m)}$ is

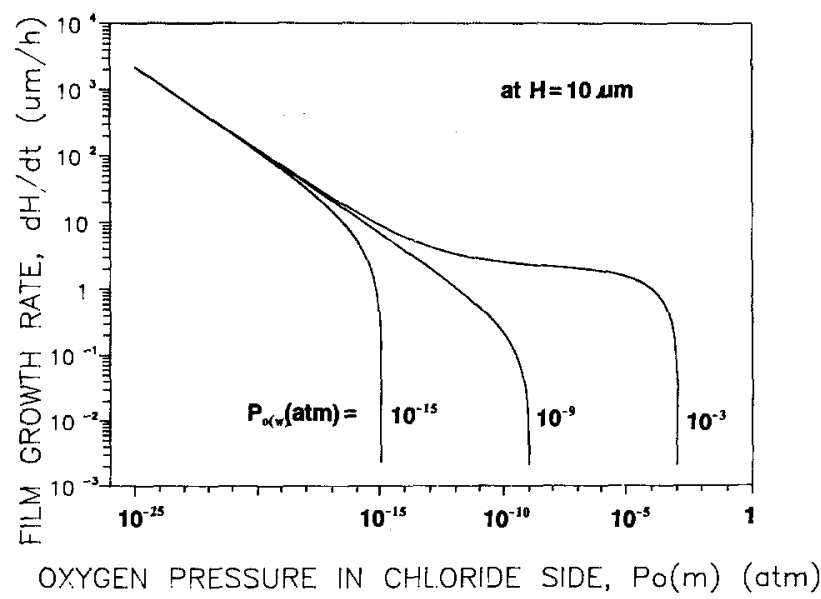

Fig. 3. Effects of oxygen pressures on the film growth rate for the rate-limiting step of bulk electrochemical transport in the EVD film.

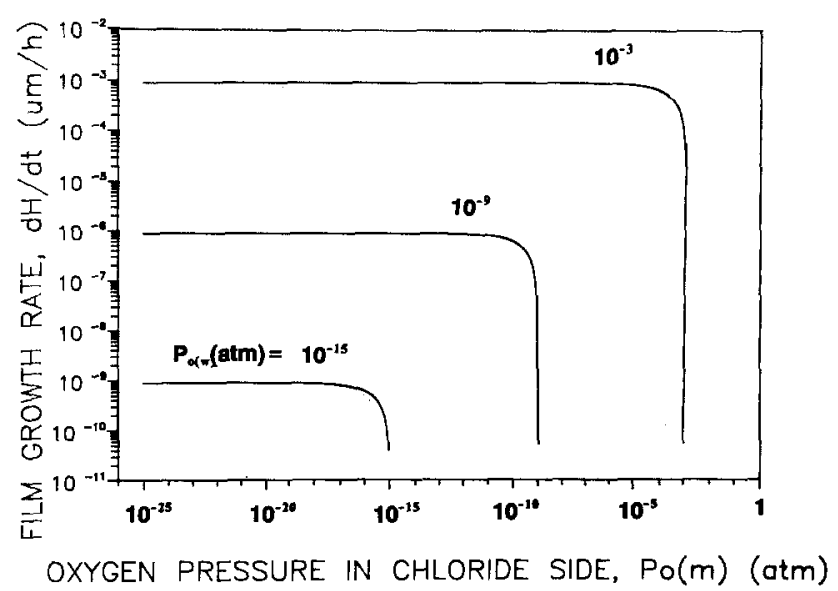

Fig. 4. Effects of oxygen pressures on the film growth rate for the rate-limiting step of interface charge-transfer reaction. 


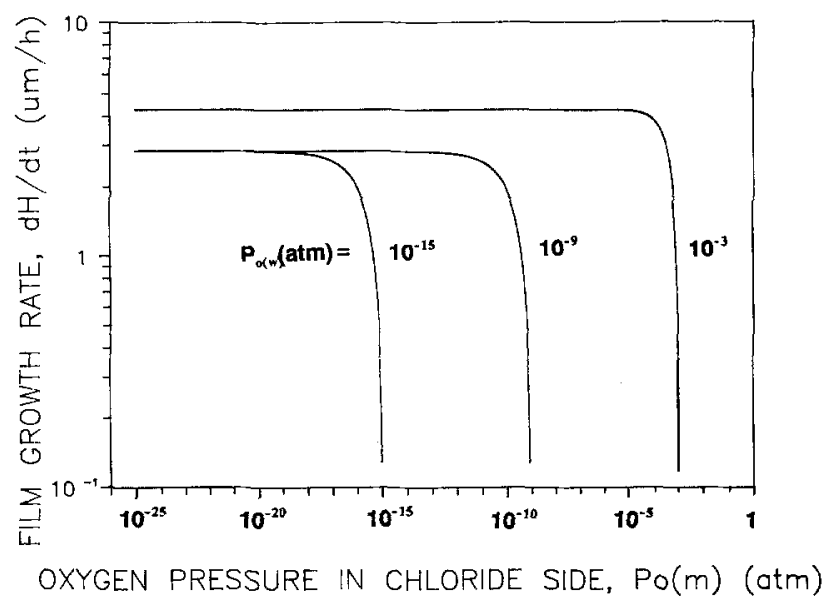

Fig. 5. Effects of oxygen pressures on the film growth rote for the rate-limiting step of water or oxygen diffusion in substrate pore.

about 2 orders of magnitude smaller than $P_{o(w)}$. The maximum growth rate is determined by

For the surface reaction as the rate-limiting step

$$
d H /\left.d t\right|_{\max }=V_{\mathrm{m}} \alpha_{2}\left[P_{o(w)}\right]^{1 / 2} / 2
$$

For the pore diffusion as the rate-limiting step

$$
\begin{gathered}
d H /\left.d t\right|_{\max }=V_{\mathrm{m}} D_{\mathrm{w}} P_{\mathrm{w}} / 2 L R T \quad \text { (for water) } \\
d H /\left.d t\right|_{\max }=V_{\mathrm{m}} D_{\mathrm{o}} P_{\mathrm{o}(\mathrm{w}} / L R T \quad \text { (for air) }
\end{gathered}
$$

Equations [17]-[19] suggest that increasing the water vapor pressure (or oxygen pressure) in the water chamber raises the growth rate. For pore diffusion as the ratelimiting step, this maximum rate is also proportional to the substrate pore size/thickness ratio $(r / L)$ since in the Knudsen diffusion regime (low pressure, high temperature, and small pore size) the effective diffusivity is directly related to the Knudsen diffusivity $D_{k}(18)$

$$
D_{\mathrm{k}}=0.97 r(T / M w)^{1 / 2}
$$

where $D_{\mathrm{k}}$ is in $\mathrm{cm}^{2} / \mathrm{s}, r$ is in $\mu \mathrm{m}$, and T in K. $M w$ is the molecule weight of the diffusing gas.

The maximum film growth rates are the same for the rate-limiting step of pore diffusion with pure water vapor or a water vapor-hydrogen mixture as the oxygen source reactant, despite the difference in $P_{o(w)}$, as shown in Fig. 5 . However, the maximum rate decreases substantially with decreasing $P_{\mathrm{o}(w)}$ for the rate-limiting step of the surface reaction. As discussed before and shown by Eq. [18] and [19], the pore diffusion can become the rate-limiting step by decreasing the substrate pore size/thickness ratio and/or oxygen source reactant pressure in the water chamber which determines the maximum growth rate. The pore diffusion as the rate-limiting step should result in: (i) a linear film thickness-deposition time relationship; (ii) constant doped oxide concentration across the EVD film; and (iii) a constant maximum growth rate with a large variation of oxygen partial pressure in the metal chloride chamber (this makes it easy to operate the experiments).

\section{Experimental Results and Discussion}

Experimental results.-The EVD experiments were performed in a homemade CVD/EVD apparatus. The central

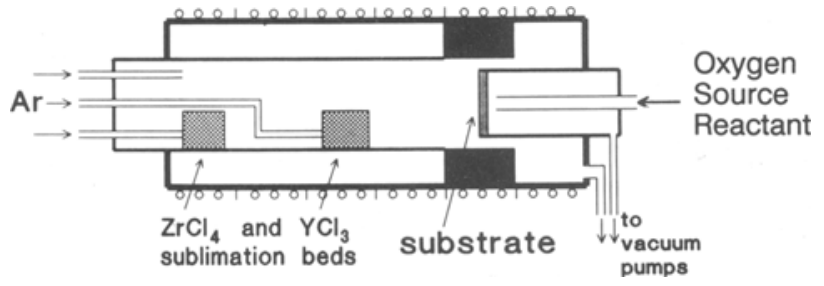

Fig. 6. A schematic diagram of the central reactor part of the EVD apparatus. part of the apparatus is a reactor made of three dense-wall alumina ceramic tubes, which were heated by a six-zone furnace to give the desired temperature profile, as shown in Fig. 6. A porous substrate disk ( $2 \mathrm{~mm}$ thick; $12 \mathrm{~mm}$ diam) was cemented onto the end of the smallest alumina tube to separate the reactor into two chambers. A mixture of the chloride vapors was generated by sublimation of powdered $\mathrm{YCl}_{3}$ and $\mathrm{ZrCl}_{4}$, which were placed inside the reactor. The partial pressures of the two chlorides were controlled by the sublimation bed temperatures and flow rates of the Ar carrier gas. The oxygen source reactant was introduced by passing $\mathrm{H}_{2}$ or air through a water sparger or using the dry air directly. The apparatus was automated so that all the experimental conditions could be well controlled.

In the EVD experiments, the reactor was first slowly heated (at a rate of about $100^{\circ} \mathrm{C} / \mathrm{h}$ ) to the desired temperature profile. The Ar streams were passed through the sublimation beds at given flow rates and the oxygen source reactant stream bypassed the reactor to the vacuum pump. When all the experimental conditions were stable, an EVD experiment was started by introducing the oxygen source reactant stream into the reactor. The initial period of the substrate pore narrowing and closure was monitored by an in situ permeation technique (5). After the pore was closed the experiment continued for an extended period of time in order for the EVD process of film growth to take place, and was terminated by stopping the oxygen source reactant stream. The reactor was then cooled down to room temperature, and the sample was removed from the tube for characterization. The film thickness was determined by scanning electron microscopy (SEM). A typical SEM photo for sample no. 23 is given in Fig 7 which clearly shows a dense top layer on the coarse substrate. The deposition of $Y S Z$ (with about 8 mole percent $(\mathrm{m} / \mathrm{o}) \mathrm{Y}_{2} \mathrm{O}_{3}$, determined by EDS) on the substrates was also confirmed with XRD.

The present experiments were focused on determining the growth rates of YSZ films with different oxygen partial pressures in the water chamber on two types of substrates with different pore dimensions. Investigating the effects of the reactant concentration (pressure) on the reaction rate is a common approach for the kinetic studies in the chemical reaction engineering. The substrate pore dimensions, experimental conditions, and determined results for the five typical cases of YSZ deposition are summarized in Table II. Other experimental conditions which are not listed in the table include: total pressure in the reactor, $\sim 10^{-3}$ atm (2 mbar); reaction temperature, $1000^{\circ} \mathrm{C}$; and chloride chamber oxygen partial pressure, $P_{o(\mathrm{~m})}=10^{-23}$ atm [using the data reported in Ref. $(2,19)$ ]. The film growth rates determined in these studies are about $1.5 \mu \mathrm{m} / \mathrm{h}$ for the smaller pore substrate and $30 \mu \mathrm{m} / \mathrm{h}$ for the composite substrate. Growth rates of about $5 \mu \mathrm{m} / \mathrm{h}$ were previously reported by other investigators $(2,4,6)$ for growing YSZ on porous substrates. As the detailed experimental conditions were not reported in those studies, it is difficult to make a quantitative comparison between this work and the previously reported work.

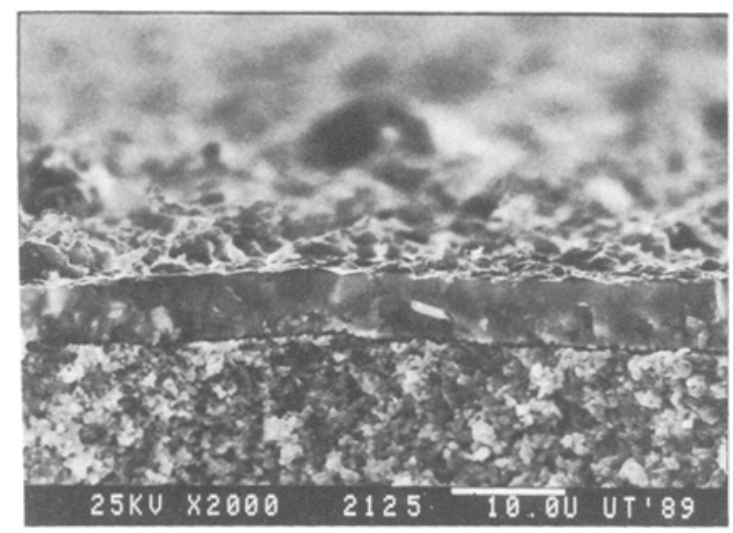

Fig. 7. SEM photograph of EVD run 23 showing a dense YSZ film with uniform thickness of about 5-6 $\mu \mathrm{m}$ on the alumina porous substrate. 
Table II. EVD experimental conditions and summary of results

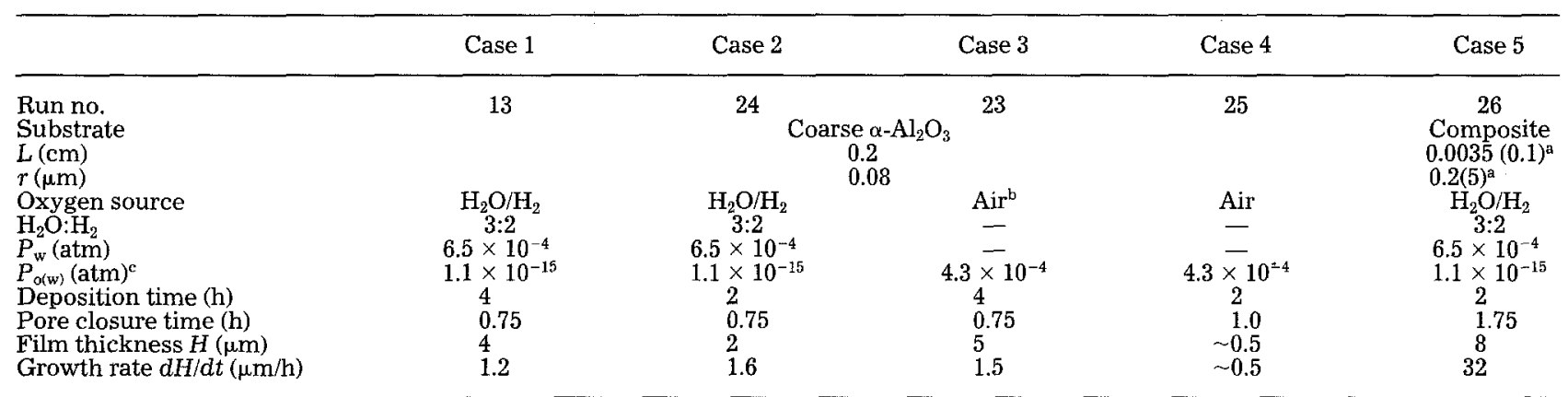

a The composite substrate consists of a coarse support and a fine top layer. The data out of and within the parenthesis are of top layer and support, respectively.

Moistened with $1.4 \%$ water.

c Calculated by $P_{\mathrm{o}(\mathrm{w})}=\mathrm{Ke}^{2}\left(P_{\mathrm{w}} / P_{\mathrm{H}}\right)^{2}$, with $\mathrm{Ke}=6.5 \times 10^{-8}$ at $1000^{\circ} \mathrm{C}$; see J. M. Smith and H. C. van Ness, "Introduction to Chemical Engineering Thermodynamics," McGraw-Hill, New York (1975).

Discussion.-Since the electrochemical properties of YSZ have been well studied $(14,16,17)$, it is possible to predict the film growth rate if $P_{o(m)}$ is known when the electrochemical transport in the EVD film is the rate-limiting step. Thus, the predicted growth rate data are given in the first row in Table III for the five cases of YSZ deposition, which were calculated with Eq. [14] (for $H=1 \mu \mathrm{m}$ ) using the electronic conductivity data listed in Table $I$ and the previously reported value of $10^{-23}$ atm for $P_{o(m)}(2,19)$. The predicted growth rates are much larger than the experimentally determined ones. This indicates that the bulk electrochemical transport may not be the rate-limiting step. Since one may argue that the larger predicted growth

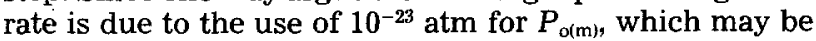
smaller than the actual $P_{\mathrm{o}(\mathrm{m})}$ in the experiments, a more detailed discussion should be given on this point.

As mentioned earlier, $P_{o(m)}$ is the oxygen partial pressure equilibrated with the following reaction at EVD film/chloride interface

$$
\left.\mathrm{O}_{2} \text { (with } P_{\mathrm{o}(\mathrm{m})}\right)+\mathrm{MCl}_{4}<==>\mathrm{MO}_{2}(\mathrm{~s})+2 \mathrm{Cl}_{2}(\mathrm{~g})
$$

Estimation of $P_{\mathrm{o}(\mathrm{m})}$ from the thermodynamic equation for this reaction is complicated by the fact that $P_{\mathrm{cl}}$ is not known for the EVD experimental processes (2-5) in which only $P_{\mathrm{mcl}}$ in the metal chloride vapor is controlled. Thus, the two unknowns $\left(P_{\mathrm{o}(\mathrm{m})}\right.$ and $\left.P_{\mathrm{cl}}\right)$ cannot be solved from this single equilibrium relation. Another relation, which is determined by the EVD experimental processes (such as reactor shape, flow pattern, etc.), should be given. With a controlled $P_{\text {mcl, }}$, the equilibrium relation for the above reaction shows that $P_{\mathrm{o}(\mathrm{m})}$ is proportional to $\left[P_{\mathrm{cl}}\right]^{2}$. A successful EVD experimental process should provide a very low $P_{c}$ value in order to lower $P_{\mathrm{o}(\mathrm{m})}$, so increasing the driving force for the film growth.

If the water is used as the oxygen source reactant, the overall reaction for the EVD process is as follows

$$
2 \mathrm{H}_{2} \mathrm{O}(\mathrm{g})+\mathrm{MCl}_{4}(\mathrm{~g})=>\mathrm{MO}_{2}(\mathrm{~s})+2 \mathrm{H}_{2}+2 \mathrm{Cl}_{2}
$$

which is generally thermodynamically unfavorable for the metal oxide formation [e.g., the standard $\Delta G^{\circ}$ for the formation of $\mathrm{ZrO}_{2}$ by this reaction is about $+220 \mathrm{~kJ} / \mathrm{mol}$ at $1000^{\circ} \mathrm{C}$ (5)]. This means that at the standard condition $P_{o(m)}$ is greater than $P_{\mathrm{o}(\mathrm{w})}$, indicating a negative driving force across the EVD film. The experimental results, however, do show the formation of $\mathrm{ZrO}_{2}$ (or YSZ) by this reaction. The reasonable explanation on this appeared-to-be contractive experimental evidence is that the extreme external conditions (most likely the very low $P_{\mathrm{cl}}$ value, as mentioned earlier) are imposed on these experiments to shift the thermodynamic equilibrium. Thus, $P_{\mathrm{o}(\mathrm{m})}$ is a processdependent parameter. $P_{o(m)}$ or $P_{c l}$ therefore should be directly measured, for example, using an oxygen sensor. But the measurements of $P_{\mathrm{o}(\mathrm{m})}$ or $P_{\mathrm{cl}}$ were found rather impractical due to the fact that the extremely reactive atmosphere in the reactor quickly consumes metallic electrodes, making it very difficult to find a reliable oxygen sensor device (6). On the other hand, it was also difficult to sample a con- siderable amount of gas from the chloride chamber for chemical analysis because the chloride chamber was operated at high temperature and low pressure. Nevertheless, in the practical EVD process the consumption rate of the metal chloride due to the EVD film growth is generally much smaller $(<0.1 \%)$ than the metal chloride sublimation rate in an EVD apparatus. This means that only a very small amount of chlorine is generated by the EVD reaction. As the EVD experiments are normally operated in a flowing system at low pressure with a relatively large carrier gas flow rate, the generated chlorine can be rapidly moved away from the chloride chamber, resulting in a rather low value of $P_{\mathrm{Cl}}$ in the chloride chamber. To ensure a positive driving force for the EVD process, it is suggested that oxygen or air (mixed with water for kinetic purposes, to be discussed next) be used as the oxygen source reactant so that $P_{\mathrm{o}(\mathrm{w})}$ can be increased substantially.

Although the actual value of $P_{o(m)}$ was not determined in the present experiments, it is certain that $P_{o(m)}$ is smaller than $P_{o(w)}$ as evidenced by the formation of a YSZ film. In addition, $P_{\mathrm{o}(\mathrm{m})}$ should be the same for the five experimental runs due to the identical process conditions in the chloride chamber in the five experiments. If the rate-limiting step was the bulk electrochemical transport, the growth rate for cases 1 and 2 should be the same as that for case 5 (same $P_{\text {o(w) }}$ and $P_{\text {o(m) }}$, but different in substrate pore dimension), and much different from that for cases 3 and 4 (same substrate pore dimension, but different $\left.P_{o(\mathrm{w})}\right)$, in order to be consistent with the theoretical prediction (Eq. [14]). The experimental results given in Table II, however, are not consistent with the theoretical prediction, suggesting that another step is rate limiting.

For the rate-limiting step of the surface reaction at the oxygen/film interface, the growth rates calculated by Eq. [13] using the data given in Tabel I for $\alpha_{2}$ are listed in

Table III. Predicted EVD film growth rate $d H / d t(\mu \mathrm{m} / \mathrm{h})$

\begin{tabular}{lccc}
\hline Rate-limiting step & Cases 1 and 2 & Cases 3 and 4 & Case 5 \\
\hline $\begin{array}{l}\text { Film bulk }(\mathrm{Eq} \text {. [14]) } \\
(\text { at } H=1 \mu \mathrm{m})\end{array}$ & 6820 & 6880 & 6820 \\
$\begin{array}{l}\text { Surface reaction } \\
\text { (Eq. [13]) }\end{array}$ & $9.3 \times 10^{-10}$ & $5.8 \times 10^{-4}$ & $9.3 \times 10^{-10}$ \\
$\begin{array}{l}\text { Pore diffusion } \\
\text { (Eq. [11] or [12]) }\end{array}$ & 1.7 & 1.6 & $118(55)^{\mathrm{c}}$ \\
\hline
\end{tabular}

${ }^{\mathrm{a}} D_{\mathrm{w}}$ or $D_{\mathrm{o}}$ values are $0.15,0.11$, and $0.18(4.5)^{\mathrm{b}} \mathrm{cm}^{2} / \mathrm{s}$ for the three conditions, respectively. The effective diffusivities are calculated by $D_{\mathrm{w}}$ (or $\left.D_{0}\right)=\epsilon D_{\mathrm{k}} / \tau$; where $\tau$ and $\epsilon$ are the substrate tortuosity and porosity. $D_{\mathrm{k}}$ is the Knudsen diffusivity, Eq. [20]. The available data of $\epsilon=0.5$ and $\tau=2$ were used for the coarse substrate (cases 1-4); in R. J. van Vuren et al., in "High Tech Ceramics," P. Vincenzini, EdiR. J. van Vuren et al., in "High Tech Ceramics," P. Vincenzini, Edi-
tor, p. 2235, Elsevier, Amsterdam (1987). For case 5 the substrate tortuosity and porosity are not available, $\epsilon=0.5$ and $\tau=4$, as suggested by C. N. Satterfield, in "Mass Transfer in Heterogeneous Catalysis," MIT Press, Cambridge, MA (1970), were used.

${ }^{b}$ Data out of and within parenthesis are the diffusivities in top layer and support, respectively.

c Data out of and within parenthesis are the growth rate predicted considering top layer only and both top layer and support, respectively. 
the second row in Table III. The predicted growth rates are much smaller than the experimental results. It should be pointed out that due to unavailability of the rate constant data $\left(\alpha_{2}\right)$ for the surface reaction at the oxygen (or water)/ EVD film interface, the predicted growth rates were calculated using the available data of Dou et al. (13) for the surface reaction at the oxygen/Ca-stabilized zirconia interface. In most studies on oxygen permeation through YSZ, e.g., Ref. (14), the surface reaction is assumed (without proof) to be much faster than the bulk diffusion. This is probably true when the YSZ pellets are relatively thick (about 1-2 mm). The work of Dou et al. appeared to be the only study considering the surface reaction in the oxygen permeation through the stabilized zirconia pellets in which they pointed out that the surface reaction can be a rate-limiting step when CSZ thickness is less than about $0.2 \mathrm{~mm}$. Therefore, the values of $\alpha_{2}$ reported by Dou et al. (13) were used in the present calculation. The discrepancy between the predicted and experimentally measured film growth rates can probably be attributed to the inconsistency between the present EVD experimental conditions and the conditions on which $\alpha_{2}$ was measured (13). For example, in the present EVD experiments, the presence of water in the oxygen source reactant may have some catalytic effects to increase the surface reaction rate. This is evidenced by the measured film growth rates of case 3 and case 4 in Table II. The film growth rate with moistened air is at least three times larger than that with dried air. Therefore it is suggested to add water to dried air (or pure oxygen) in order to raise the surface reaction rate. An experimental program has been started in this laboratory to investigate the surface reaction at the interface of oxygen (or water)/EVD-grown YSZ film and oxygen permeation through the very thin EVD-grown YSZ films. The preliminary results of the oxygen permeation study (20) suggest that the surface reaction step is not the rate-limiting step for the oxygen transport through the very thin EVD-grown YSZ films. This, in fact, is also supported by the present experimental results that YSZ film growth rate is essentially independent of the oxygen partial pressure $P_{\mathrm{o}(\mathrm{w})}$ (compare case 2 and case 3 in Table II). It is obvious from the theoretical analysis that film growth rate should be proportional to $P_{o(w)}{ }^{1 / 2}$ if the surface reaction step was rate limiting.

Finally we assume that the oxygen (or water) diffusion in the substrate pores is the rate-limiting step. The predicted results calculated by Eq. [11] for water or by Eq. [12] for oxygen are listed in the third row in Table III. A remarkably good agreement is found between the predicted film growth rates and the experimentally determined ones for all five cases. This suggests that the pore diffusion may be the rate-limiting step for the EVD process in the present EVD experiments. Under present experimental conditions, the oxygen partial pressure has essentially no effects on the film growth rate. The pressure of the oxygen source reactant (e.g., water, or oxygen if the air is used) and substrate pore dimension determine the film growth rate.

\section{Conclusions}

New experimental results and a more systematic theoretical analysis were presented which improved the understanding of the kinetics of the EVD process for growing thin YSZ film on porous substrates. The experimental work was focused on the effects of the oxygen partial pressure and substrate pore size on the EVD film growth rates. The theoretical analysis, based on a model taking into account the pore diffusion, interface chargetransfer reaction, and bulk electrochemical transport, and the experimental results show that the pressure of the oxygen source reactant, oxygen partial pressure, and substrate pore dimension are important in affecting the ratelimiting step and the film growth rate.

The difference of effects of oxygen partial pressure on the film growth rate with different rate-limiting steps is theoretically investigated. The EVD film thickness-deposition time relation may vary from parabolic to linear, depending on which step is the rate-limiting step. The experimental results show that water vapor or oxygen diffusion is the rate-limiting step in the EVD process for depositing
YSZ film under the present experimental conditions (i.e., low pressure of oxygen source reactant and small substrate pore size/thickness ratio).

\section{Acknowledgments}

These investigations were partly supported by the Dutch Ministry of Economical Affairs (Research Project "ECVD Synthesis and Properties of Porous Composite Systems," IOP Technical Ceramics No. 87 A045) and partly performed under contract with the Commission of the European Communities (CEC) within the Non-Nuclear Energy R and D Programme (Research Contract "Membrane Based Thin Layer SOFC Technology," No. EN3E0175-NL). Mr. P. Fransen and Mr. R. Kuipers are acknowledged for assistance in running the experiments.

Manuscript submitted Dec. 27, 1989; revised manuscript received June 6,1990 . This was Paper 536 presented at the Hollywood, FL, Meeting of the Society, Oct. 15-20, 1989.

The University of Twente assisted in meeting the publication costs of this article.

\section{LIST OF SYMBOLS}

$D_{0}$ effective diffusivity of oxygen in substrate pore, $\mathrm{cm}^{2} / \mathrm{s}$

$D_{\mathrm{k}} \quad$ Knudsen diffusivity, $\mathrm{cm}^{2} / \mathrm{s}$

$D_{\mathrm{w}}$ effective diffusivity of water in substrate pore, $\mathrm{cm}^{2} / \mathrm{s}$

F Faraday constant

$H \quad$ EVD film thickness, $\mu \mathrm{m}$

$J_{i} \quad$ oxygen $\left(1 / 2 \mathrm{O}_{2}\right.$ or $\left.\mathrm{O}^{2-}\right)$ flux at different step $(\mathrm{i}=1,2$, $3,4)$ of the EVD process, $\mathrm{mol} / \mathrm{cm}^{2} \cdot \mathrm{s}$

$J_{1(\mathrm{w})} \quad$ water vapor flux in substrate pore, $\mathrm{mol} / \mathrm{cm}^{2} \cdot \mathrm{s}$

$K$ parabolic rate constant for the film growth, $\mu \mathrm{m}^{2} / \mathrm{s}$

$L \quad$ substrate disk thickness, $\mathrm{mm}$

$P_{\text {o(w) }}$ oxygen $\left(\mathrm{O}_{2}\right)$ partial pressure in the water chamber, atm

$P_{\text {o(1) }}$ oxygen $\left(\mathrm{O}_{2}\right)$ partial pressure at the inner end of substrate pore, atm

$P_{\text {o(2) }}$ oxygen $\left(\mathrm{O}_{2}\right)$ partial pressure in the EVD film at $\mathrm{Z}=\mathbf{0}$, atm

$P_{\mathrm{o}(3)}$ oxygen $\left(\mathrm{O}_{2}\right)$ partial pressure in the EVD film at $Z=H$, atm

$P_{o(m)}$ oxygen $\left(\mathrm{O}_{2}\right)$ partial pressure in the metal chloride chamber, atm

$P_{\mathrm{cl}} \quad$ partial pressure of chlorine $\left(\mathrm{Cl}_{2}\right)$ in the metal chloride chamber, atm

$P_{m c l} \quad$ partial pressure of metal chloride vapor in the chloride chamber, atm

$P_{\mathrm{w}} \quad$ partial pressure of water vapor in the water chamber, atm

$P_{\mathrm{w}(1)} \quad$ water vapor pressure at the inner end of the substrate pore, atm

$R \quad$ gas constant

$r$ average substrate pore radius, $\mu \mathrm{m}$

$T$ reaction temperature, $\mathrm{K}$

$t$ deposition time, $s$ or $h$

$t_{\mathrm{i}} \quad$ oxygen ion transfer number in the EVD film

$V_{m}$ molar volume of the metal oxide of the EVD film, $\mathrm{cm}^{3} / \mathrm{mol}$

$Z$ position along EVD film growing direction, $\mathrm{mm}$

$\alpha_{2} \quad$ overall rate constant for the reduction chargetransfer reaction, $\mathrm{mol} / \mathrm{cm}^{2} \cdot \mathrm{s} \cdot \mathrm{atm}^{1 / 2}$

$\alpha_{4} \quad$ overall rate constant for the oxidation charge transfer reaction, $\mathrm{mol} / \mathrm{cm}^{2} \cdot \mathrm{s} \cdot \mathrm{atm}$

$\sigma_{e} \quad$ electronic conductivity in the EVD film, $\Omega^{-1} \mathrm{~cm}^{-1}$

$\sigma_{n}{ }^{o}$ free-electron conductivity in the EVD film at $1 \mathrm{~atm}$ of oxygen partial pressure, $\Omega^{-1} \mathrm{~cm}^{-1} \mathrm{~atm}^{-1 / 4}$

$\sigma_{p}{ }^{o} \quad$ hole conductivity in the EVD film at 1 atm of oxygen partial pressure, $\Omega^{-1} \mathrm{~cm}^{-1} \mathrm{~atm}^{1 / 4}$

$\mu_{0} \quad$ chemical potential of oxygen in EVD film, $\mathrm{J} / \mathrm{mol}$

\section{REFERENCES}

1. B. C. H. Steele, "Ceramic Electrochemical Reactors, Current Status and Application," Ceramionies, Surrey, England (1987)

2. A. O. Isenberg, in "Electrode Materials and Processes for Energy Conversion and Storage," PV 77-6, J. D. E. McIntyre, S. Srinivasan, and F. G. Will, Editors, p. 572, The Electrochemical Society Softbound Proceedings Series, Princeton, NJ (1977).

3. G. Dietrich and W. Schäfer, Int. J. Hydrogen Energy, 9, 747 (1984). 
4. M. F. Carolan and J. M. Michaels, Solid State Ionics, 25, 207 (1987).

5. Y. S. Lin, L. G. J. de Haart, K. J. de Vries, and A. J. Burggraaf, in "Euro-ceramics," Vol. 3, "Engineering Ceramics," G. de With, R. A. Terpstra, and R. Metselaar, Editors, p. 3. 590, Elsevier, Amsterdam (1989).

6. M. F. Carolan and J. M. Michaels, Solid State Ionics, 37, $189(1990)$.

7. Y.S. Lin, K. J. de Vries, and A. J. Burggraaf, J. de Phys. Coll., 50(5), 861 (1989).

8. P. Kofstad, "High-Temperature Oxidation of Metals," Chap. 5, John Wiley and Sons, New York (1966).

9. L. Heyne, in "Solid Electrolyte," S. Geller, Editor, p. 169, Springer-Verlag, Berlin (1977).

10. J. H. Enloe and G. P. Wirte, This Journal, 133, 1583 (1986).

11. M. F. Carolan and J. M. Michaels, Solid State Ionics, 37,
197 (1990).

12. J. Crank, "The Mathematics of Diffusion," p. 44, Oxford University Press, London (1975)

13. S. Dou, C. R. Masson, and P. D. Paccy, This Journal, 132, 1843 (1985)

14. J. H. Park and R. N. Blumenthal, ibid., 136, 2867 (1989)

15. J. Audry-Sauchez, Can. J. Chem. Eng., 66, 1031 (1988).

16. S. F. Palguev, V. K. Gilderman, and A. D. Neujmin, This Journal, 122, 747 (1975).

17. M. Kleitz, E. Fernandez, J. Fouletier, and P. Fabry, Adv. Ceram., 3, 349 (1981).

18. J. B. Butt, "Reaction Kinetics and Reaction Design," p. 390, Prentice-Hall, Englewood Cliffs, NJ (1980).

19. A. O. Isenberg, Solid State Ionics, 3/4, 431 (1981).

20. Y. S. Lin, K. J. de Vries, and A. J. Burggraaf, Proceedings of the International Congress on Membranes, Chicago, IL, Aug. 20-24, 1990, Vol. 1, p. 552.

\title{
Divalent Europium-Activated Barium Magnesium Silicate Phosphors: Improvement and Characterization
}

\author{
Tuan A. Dang, Anthony F. Kasenga, ${ }^{\star}$ and Charles F. Chenot ${ }^{\star}$ \\ GTE Products Corporation, Chemical and Metallurgical Division, Towanda, Pennsylvania 18848
}

\section{ABSTRACT}

Divalent europium-activated barium magnesium silicate phosphor $\left(\mathrm{BaMg}_{2} \mathrm{Si}_{2} \mathrm{O}_{7}: \mathrm{Eu}\right)$ has been significantly improved by either refiring or rewashing. The greatest improvement was obtained when the phosphor was refired with $\mathrm{NH}_{4} \mathrm{~F}$ flux and rewashed with $\mathrm{KOH}$. This reprocessing resulted in a fluorescent lamp of higher maintenance and a lamp output of $100 \mathrm{~h}$, twice that of the original phosphor. Surface characterization of treated phosphors using ESCA indicated a dramatic change in the surface chemistry as a result of reprocessing. A strong correlation between phosphor surface composition and lamp performance was observed.

Divalent europium-activated barium magnesium silicate, also known as Sylvania Type 217 phosphor, was first developed by Barry (1). It is generally used in fluorescent lamps, for photocopy applications. Excitation of the phosphor using $254 \mathrm{~nm}$ radiation will result in an emission band at $398 \mathrm{~nm}$ whose width at half-height is $24 \mathrm{~nm}$. Phosphor prepared using Barry's procedure generally has poor $100 \mathrm{~h}$ lamp performance, with maintenance of about $50 \%$ and radiant output of approximately $3000 \mathrm{~mW}$ in the UV region.

Reprocessing of this phosphor by refiring and/or rewashing has resulted in a significant improvement in both lamp output and maintenance. An increase of up to $20 \%$ on oh output is observed for a lamp made of phosphor subjected to this procedure. Improvement at $100 \mathrm{~h}$ is even more significant. Lamp output is doubled when reprocessing is applied.

To understand the mechanism for this improvement, we have used electron spectroscopy for chemical analysis (ESCA) to characterize the surface, and x-ray diffraction spectrometry (XRD) and atomic absorption spectroscopy (AA) to study the bulk composition of the phosphor. Results of these analyses have shown that reprocessing has little effect on bulk chemistry, but it dramatically changes the phosphor's surface composition. A strong correlation between surface composition and lamp performance has been observed. ESCA has been extensively used in material characterization (2-7), but its application in phosphor study has been limited (8-10). In this paper, we will illustrate the usefulness of ESCA in the study of divalent europium-activated barium magnesium silicate phosphors. The effects of processing treatments on the phosphor's surface chemistry and the relationship between results of surface characterization and lamp performance will be discussed.

\section{Experimental}

Detailed discussion of the phosphor preparation can be found in the Appendix. Barry's procedure (1) was followed

*Electrochemical Society Active Member. in preparation of the conventional divalent europium-activated barium magnesium silicate phosphor. Reprocessing was achieved through rewashing and/or refiring with or without flux. Procedures for rewashing and refiring are similar to the original washing and firing steps used in the phosphor synthesis. Rewashing was done in a $\mathrm{KOH}$ solution at $60^{\circ} \mathrm{C}$ for $2 \mathrm{~h}$. After $\mathrm{KOH}$ washing, the phosphor was repeatedly washed with deionized water until the $p H$ wash was less than 10.0. The sample was then filtered and ovendried. Refiring was carried out in a $33 \% \mathrm{H}_{2} / 67 \% \mathrm{~N}_{2}$ atmosphere at $1230^{\circ} \mathrm{C}$ for $200 \mathrm{~min}$. When flux was used, ammonium fluoride $\left(\mathrm{NH}_{4} \mathrm{~F}\right)$ was blended with the phosphor.

Lamp tests were performed on the materials to determine their worth as commercial products. A standard phosphor $\left(\mathrm{Sr}_{2} \mathrm{P}_{2} \mathrm{O}_{7}: \mathrm{Eu}\right)$ was included in each measurement as a control. The UV output in $\mathrm{mW}$ from 300 to $480 \mathrm{~nm}$ was recorded for each lamp at 0 and $100 \mathrm{~h}$ of operation. Maintenance, which demonstrates a lamp's ability to preserve its output during operation, is defined as the ratio of the output at $100 \mathrm{~h}$ to that at $0 \mathrm{~h}$. For each lamp, the output and maintenance were also compared to the control lamp and the differences $(\Delta)$ were calculated. The normalized $\Delta$ value is generally a better indicator for evaluating the lamp performance, because it has been corrected for differences in lamp processing conditions.

ESCA analyses were carried out on a Physical Electron-

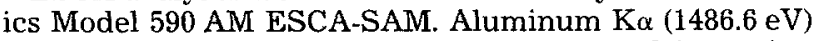
radiation from the dual anode source was used for excitation in ESCA studies. The spectrometer was operated at $15 \mathrm{kV}$ and $300 \mathrm{~W}$ and the base system pressure was below $5 \times 10^{-9}$ torr. Binding energies were referenced to the Cls peak at $284.6 \mathrm{eV}$. Integrated peak areas were converted to atomic percentages using atomic sensitivities provided by Physical Electronics. The sputtering was carried out using a $3-\mathrm{keV} \mathrm{Ar}+$ ion gun rastered over an area of $10 \times 10 \mathrm{~mm}$. Sputtering rate calibrated against $\mathrm{Ta}_{2} \mathrm{O}_{5}$ at this condition is $5 \AA / m i n$. X-ray diffraction results were obtained using a Rigaku D/Max automated diffractometer. Bulk composition was determined using a Perkin Elmer Model 5000 atomic absorption spectrophotometer. 